\title{
Initial Administration Of TPA For Ischemic Stroke In Atieh Hospital
}

Majid Sabahi $(M D)^{1 *}$, Saeid Ghazvinian $(M D)^{2}$, M ohammadAli Hamiditabar $(M D)^{3}$, Saeid Bayat $(M D)^{4}$, NadiaAmalia Hakim ${ }^{5}$

${ }^{1}$ ACLS Course Director, Sunny Brook hospital, University of Toronto, Canada.

${ }^{2}$ Nuerologist, Chief and Director of Neurology Department and Neurolab, Atieh Hospital, Tehran, Iran.

${ }^{3}$ Director of Clinical Research in Excel Diagnostics and Nuclear Oncology Center, Houston, Texas.

${ }^{4}$ Neurology Researcher, Tehran University of M edical Sciences, Tehran, Iran.

${ }^{5}$ M S Public Relations, Houston, Texas.

*Corresponding Author: Email: majsabahi@yahoo.com

Fibrinolytic therapy has a crucial role in decreasing morbidity and mortality of patients who suffer from ischemic stroke.

The primary goal of therapy in acute ischemic stroke is to preserve tissue in the ischemic penumbra, where perfusion is decreased but sufficient to stave off infarction. Tissue in this area of oligemia can be preserved by restoring blood flow to the compromised area and optimizing collateral flow.(4).

Recombinant tissue-type plasminogen activator or TPA is a well-known medication for improving neurologic outcome in these patients.

We present an acute ischemic stroke case, whom we started loading dose of TPA in the Emergency Room and continued maintenance dosage in the assigned Stroke ICU. She made a great recovery when she discharged from the hospital after one week and became independent in her daily activity when we met her after few months.

Key words: Stroke, Ischemic Stroke, TPA, Ischemic, Initial Administration, Atieh Hospital, Case Report

DOI: $10.7575 /$ aiac.abcmed.ca1.5

Published Date: February 2017

Peer-review is under responsibility of the 9th Iranian Stroke Congress.

Published by Australian International Academic Centre, Australia

This published work is open access under the CC BY license.

Available online at www.abcmed.aiac.org.au 